\title{
EVALUATION OF UTILIZATION \& FACTORS AFFECTING UTILIZATION OF NEONATAL RESUSCITATION PROGRAM (NRP) AMONG THE NURSES
}

KEY WORD: Utilization, Personal profile, Nurses, Health care establishment.

\section{Mr. Dipti Y. Sorte Associate Professor, Swami Rama Himalayan University, Dehradun.}

\section{Dr. Anurag Bhai}

Patidar*

\section{Professor, C. O.N.B.M.H.R.C,Bhopal. ${ }^{*}$ Corresponding Author}

Introduction: The child age and newborn death rate lower down substantially in the last 10 years. Still if we see the death rate of new born is at top. We are losing roughly three out of two newborns every year in first four week of their life therefore, initial time in newborns transition very crucial in survival of newborns specially those who are birth asphyxiated. Purposes: Overall resolution of this research is to recognize an "Utilization, means, effective use of workshop in the professional career" among the nurses working in various healthcare establishment and factors affecting poor utilization therefore, it will help to develop any new measures or modify current workshop protocols study was conceptualized based on The health promotion model presented by Nola J Pender (1982, revised 1996). Materials \& methods: This is cross-sectional study used Quantitative research approach, to identify the utilization and association between Personal profile of nurses \& Utilization of the NRP Training Programme. Non-experimental cross - sectional research and Exploratory survey design was used where entire tool was made in Google form and send to participants mail id. study was conducted in different national healthcare establishments. The population under this study are registered nurses working in selected healthcare establishments. samples are Staff Nurses working in different Health establishments. Sample size was 278 nurses was taken from a Actual population, 300 nurses was Selected and administrated the tool and 1000 nurses was a Target population. Purposive Sampling technique was used. Tool contains Part 1 for Questionnaire for Socio-demographic assessment. Part 2 for Structured Questionnaire Utilization of NRP training Programme. The reliability of a tool was conducted for the degree of steadiness with which it measures the qualities it is supposed to quantify, Cronbach alpha $(r=0.91)$, split half correlation $(0.90)$, Spearman-brown prophecy (0.94), Mean for test (81.7) \& SD for test is 18.83. Pretesting was done 30 samples to establish the clearness of items, considerate of the linguistic and period required to ample the item. Pilot testing was conducted on nurses of different health establishments on for 30 participants. Administrative permission was obtained from NRP President Main study collected on 278 samples Proceeds for Data Analysis (Descriptive \& Inferential) as per objectives. Conclusion: The study concluded with finding Association between utilization with selected Socio-demographic (Personal profile) where Age and primary education of the participants came significant results and Participants exposure to related work area after or before NRP training are associated with the utilization NRP skills.

\section{INTRODUCTION:}

The child age and newborn death rate lower down substantially in the last 10 years. Still if we see the death rate of new born is at top. We are losing roughly three out of two newborns every year in first four week of their life therefore, initial time in newborns transition very crucial in survival of newborns specially those who are birth asphyxiated

Almost all newborns frequently obtain the best care consideration. It is now to be considered that they required special care isolated from their mother to guarantee healthy and new start of life. The instant causes of newborns deaths are primarily birth asphyxia, infection, and complications related to congenital anomaly and prematurity. Maximum neonatal deaths are prevented with simple solutions and do not required to be highly sophisticated instruments and specialized professionals ${ }^{2}$

Operative newborn care is a central challenge which is a challenged to all health worker who are working in pediatric and labour room dealing in. The concern education and simulation practice to health care team member is an essential.

The important constituent is to prepare attendants with essential psychomotor skills to enhance execution of excellence provision. The govt. office of fly welfare was speaking it through launching Navjaat shishu suraksha Karykram (NSSK). modest accessible educative element on $\mathrm{NRP}$ is established

\section{LITERATURE REVIEW:}

Dr. Suresh Ray 2014 studied utilization and awareness of National rural health mission services of rural people as he was though of the countryside people were using this facility but investigation stated that there is the average utilization of services. He also identified some of the factors are responsible for non-utilization of the services. As the search was on huge sample size in four different districts. This study supports current study ${ }^{4}$.

Luo YF et.al Concerning e health and its literacy is became a popular in health care field sply in pandemic of corona we have seen the number of people benefitted the health care facilities through $e$ health services. The interaction between people and physician has increase through telephone, messages. This study explored the outcome of three levels that is critical level, functional level and interactive of health literacy. The sample size was 489 collegiate students administered Likert's scale of 10 and 12 items in instrument. Multiple regression analysis was used to investigate association and utilization. Result show that all the three levels found $P=<0.05$ related to health care services utilization. Study concluded with e health literacy was high in outpatient department among students. Samples weaken the sex disparities for the utilization of health care services among students

\section{PROBLEM STATEMENT AND OBJECTIVES:}

3.1 Statement: "A study to assess the Utilization and Factors affecting Utilization of NRP Programme among the nurses working at different Healthcare establishment in the state of Uttarakhand"

\subsection{Objectives:}

1.To assess the utilization of the NRP training Programme among the nurses working at different healthcare establishments. 
2. To associate the finding of utilization with selected Sociodemographic (Personal Profile) variables.

\section{HYPOTHESIS:}

$\mathbf{H}_{1:}$ Significant connotation among skill Utilization of NRP Programme by nurses and selected Socio-demographic (Personal variables) of nurses.

$\mathbf{H}_{0:}$ There will be no significant association between skill Utilization of NRP Programme by nurses and selected Sociodemographic (Personal Profile) variables of nurses.

\section{CONCEPTUAL FRAMEWORK:}

Major components of General System Theory are as given below

The health promotion model presented by Nola J Pender (1982, revised 1996). In this model, these are the main dimensions that define Pender's health promotion model.

1.Individual characteristics and experiences

2.Behavior specific cognition and affect

3. Behavioral outcome

\section{MATERIALS AND METHODS:}

This is cross-sectional study used Quantitative research approach, to identify the utilization and association between Personal profile of nurses \& Utilization of the NRP Training Programme. Non-experimental cross - sectional research and Exploratory survey design was used where entire tool was made in Google form and send to participants mail id. study was conducted in different national healthcare establishments. The population under this study are registered nurses working in selected healthcare establishments. samples are Staff Nurses working in different Health establishments. Sample size was 278 nurses was taken from a Actual population, 300 nurses was Selected and administrated the tool and 1000 nurses was a Target population. Purposive Sampling technique was used. Tool contains Part l for Questionnaire for Socio-demographic assessment. Part 2 for Structured Questionnaire Utilization of NRP training Programme. The reliability of a tool was conducted for the degree of steadiness with which it measures the qualities it is supposed to quantify, Cronbach alpha $(r=0.91)$, split half correlation (0.90), Spearman-brown prophecy (0.94), Mean for test (81.7) \& SD for test is 18.83. Pretesting was done 30 samples to establish the clearness of items, considerate of the linguistic and period required to ample the item. Pilot testing was conducted on nurses of different health establishments on for 30 participants. Administrative permission was obtained from NRP President Main study collected on 278 samples Proceeds for Data Analysis (Descriptive \& Inferential) as per objectives.

\section{ANALYSIS AND INTERPRETATIONS:}

The entire data subdivided to see the systematic output of the given objective, as the objective is to assess the utilization of the NRP training Programme among the nurses where subdivisions are made as:

- Total Utilization of NRPTraining Programme.

- If skills were utilized then, the intensity in terms of Good, Moderate \& Poor of Utilized skills of NRP Training Programme.

- If skills are utilized or not utilized then, whether the participants received an opportunity to utilize their skills?

- If the NRP skills are not utilized then, what is the participant's reasons for non-utilization of skills of NRP Training Programme?

- Through the NRP skills were not utilized are the Participants still interested in renewal \& Utilization of the Course?

- Lastly, those who are utilized their NRP skills are the Participants who Stepped forward towards NRP course renewal.
Table 1: Total Utilization of NRP training Programme ( $\mathrm{n}=278)$

\begin{tabular}{|c|c|c|c|c|}
\hline \multirow[t]{2}{*}{ Particular } & \multicolumn{2}{|c|}{ Utilized } & \multicolumn{2}{|c|}{ Not utilized } \\
\hline & 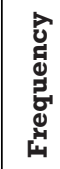 & 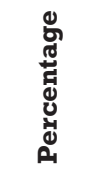 & 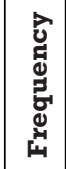 & 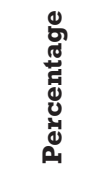 \\
\hline $\begin{array}{l}\text { NRP training skills Utilized by } \\
\text { Nurses }\end{array}$ & 163 & $58.62 \%$ & 115 & $41.36 \%$ \\
\hline
\end{tabular}

The above table shows that somehow, the majority 163 (58.63\%) nurses utilized the NRP training skills and 115 (41.36\%) nurses could not able to utilize the NRP training skills adequately. It also indicated the NRP training Programme was utilized among nurses working in different health establishment. The utilized skills nurses had exposure to your NRP skills, renewed the Course post certificate expiration, Willingness to renew NRP course in future, No difficulties/setbacks for the renewing the NRP course, Having difficulties and set back they are ready to renew the NRP course, Participants had an opportunity to demonstrate NRP training skills, Participants were willing to utilize your NRP skills aggressively after they renew their NRP Course. These are some of the points where participants agreed positively that depicts the utilization of NRP skills. Those who not utilized are given some negative responses thus the percentage comes out of non-utilization but, the good output is the majority of participants had the utilization of NRP skills.

Table 2: Intensity of Utilized skills of NRP training Programme $(n=163)$

\begin{tabular}{|c|c|c|c|c|c|}
\hline \multicolumn{6}{|c|}{$\begin{array}{l}\text { Intensity of Utilized skills of NRP training Programme } \\
\text { Total } 163(58.62 \%)\end{array}$} \\
\hline \multicolumn{2}{|l|}{ Good } & \multicolumn{2}{|c|}{ Moderate } & \multicolumn{2}{|l|}{ Poor } \\
\hline 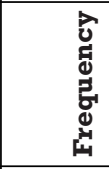 & 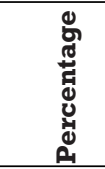 & 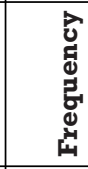 & 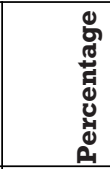 & 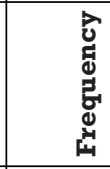 & 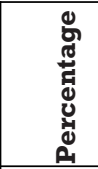 \\
\hline 53 & $19.06 \%$ & 26 & $9.35 \%$ & 84 & $30.21 \%$ \\
\hline
\end{tabular}

The above table shows that the Intensity (Good, moderate, poor) of Utilized skills of the NRP training Programme so, total of $163(58.62 \%)$ participants found to utilized their skills this was responded when the researcher asked question on exposure to their NRP skills and the majority participants 84 $(30.21 \%)$ has utilized poorly the skills of NRP training Programme whereas, $53(19.06 \%)$ responded that they were utilized the skills in Good category and 26 (9.35\%) are utilized skills moderately. It attracts the attention for motivation on Good utilization of skills also need to see the opportunities of utilization.

Table 3: Participant's Received \& utilized an Opportunities of NRP skills. $(n=278)$

\begin{tabular}{|l|l|l|l|l|}
\hline \multirow{2}{*}{ Particulars } & \multicolumn{2}{|l|}{ Yes } & No \\
\cline { 2 - 5 } & Frequency & $\%$ & Frequency & $\%$ \\
\hline $\begin{array}{l}\text { Participants received } \\
\text { opportunity to } \\
\text { demonstrate NRP skills. }\end{array}$ & 114 & $41 \%$ & 164 & $59 \%$ \\
\hline
\end{tabular}

The above table shows that the participants received \& used Opportunities for utilization. The researcher when asked question whether they received the opportunity to demonstrate their NRP skills where the majority 164(59\%) responded 'No' and $114(41 \%)$ responded 'Yes'. It shows that there is a need to put attention to the provision of opportunities for utilizing their NRP skills. It is also important to see that the reasons why skills are not utilized. 

Table 4: Participant's Reasons Of Non-utilization Of Skills Of Nrp Training Programme (n=115)

\begin{tabular}{|c|c|c|c|c|c|c|c|}
\hline \multicolumn{8}{|c|}{ Reasons of non-utilization of skills of NRP training Programme } \\
\hline \multicolumn{2}{|c|}{$\begin{array}{l}\text { Lack of opportunity in } \\
\text { current set up }\end{array}$} & \multicolumn{2}{|l|}{ No Interest } & \multicolumn{2}{|c|}{$\begin{array}{l}\text { I feel no benefit in doing } \\
\text { this course }\end{array}$} & \multicolumn{2}{|c|}{$\begin{array}{l}\text { No DifficultiesNo } \\
\text { Difficulties }\end{array}$} \\
\hline Frequency & Percentage & Frequency & Percentage & Frequency & Percentage & Frequency & Percentage \\
\hline 50 & $43.47 \%$ & 9 & $7.83 \%$ & 4 & $3.48 \%$ & 52 & $45.22 \%$ \\
\hline
\end{tabular}

The above table shows that the participant's data exhibited Reasons for non-utilization of skills of the NRP Training Programme. The researcher when enquired on participant feel any 'difficulties/setback' on renewing the NRP course the majority $52(45.22 \%)$ participants responded no difficulties but almost equivalent data 50(43.47\%) also shows that there is a lack of opportunity in the current set up where they are practice, that might because they posted outside the pediatric unit where usually find fewer opportunities for demonstrating the skills of NRP. It also put the attention when hospitals are providing such valuable skills, it is important to post them (participant) regularly in pediatric set up so, that the skills were utilized. 9 participants are responded that they are having 'No interest' And lastly very few 4(3.48\%) participants responded they 'I feel no benefit in doing this course' It is also necessary to see the out of 278 participants how many are interested to renew the course and utilize the skills.

Table 5: Participants Interested In Renewal \& Utilization Of Course [q21,23,25] $(n=278)$

\begin{tabular}{|l|l|l|l|l|l|}
\hline \multicolumn{2}{|l|}{ Particulars } & Yes & No \\
\cline { 3 - 6 } & Frequency & $\%$ & Frequency & $\%$ \\
\hline 2 & $\begin{array}{l}\text { Participants willing } \\
\text { to renew the NRP } \\
\text { Course }\end{array}$ & 239 & $\begin{array}{l}85.97 \\
\%\end{array}$ & 39 & $\begin{array}{l}14.0 \\
2 \%\end{array}$ \\
\hline $\begin{array}{l}\text { Inspite of } \\
\text { difficulties } \\
\text { /setbacks willing to } \\
\text { renew the NRP } \\
\text { course }\end{array}$ & 235 & $\begin{array}{l}84.53 \\
\%\end{array}$ & 43 & $\begin{array}{l}15.4 \\
6 \%\end{array}$ \\
\hline $\mathbf{3}$ & $\begin{array}{l}\text { Once renew willing } \\
\text { to utilize skills } \\
\text { aggressively }\end{array}$ & 246 & $\begin{array}{l}88.48 \\
\%\end{array}$ & 32 & $\begin{array}{l}11.5 \\
1 \%\end{array}$ \\
\hline
\end{tabular}

The above table shows researchers enquiry 'Course renewal \& Utilization of NRP skills' then it reveals that out of 278 participants how many participants are interested in course renewal \& Utilization of NRP skills' on three major aspects the response of participants received and depicted in above table which shows that majority $246(88.48 \%)$ participant replied 'Yes' they are interested and 'Once it renew they are willing to utilize skills aggressively' whereas minimum 32 $(11.51 \%)$ participants replied 'No' they are not interested in the utilization of skills aggressively. Secondly, majority $239(85.97 \%)$ participants responded 'Yes' they are willing to renew the NRP course and a minimum of $39(14.02 \%)$ responded 'No' they are not willing to renew the NRP course whereas a minimum of 235(84.53\%) participants replied 'Yes' Inspite of difficulties /setbacks they are willing to renew the NRP course. It shows that participants are interested in the utilization of NRP skills. It is also important to see that the interested participants are taken any step towards the renewal of the NRP course.

Table 6: Participants Interested Stepping Towards Nrp Course Renewal [q20] (n=278)

\begin{tabular}{|c|c|c|c|c|}
\hline \multirow[t]{2}{*}{ Particulars } & \multicolumn{2}{|l|}{ Yes } & \multicolumn{2}{|l|}{ No } \\
\hline & \begin{tabular}{|l|} 
Frequency \\
\end{tabular} & $\%$ & Frequency & $\%$ \\
\hline $\begin{array}{l}\text { Post certificate } \\
\text { expiration } \\
\text { Participants attended } \\
\text { NRP course }\end{array}$ & 77 & \begin{tabular}{|l|}
27.79 \\
$\%$
\end{tabular} & 201 & $\begin{array}{l}2.30 \\
\%\end{array}$ \\
\hline
\end{tabular}

The above table shows that the interested participants took steps towards NRP course renewal and the majority $201(72.30 \%)$ participants responded 'No' to 'Post certificate expiration participants attended NRP course' and a minimum

of $77(27.79 \%)$ responded 'Yes' to 'Post certificate expiration Participants attended NRP course'. It means very few candidates took interest to renew the NRP course. As it also shows that that the pediatric area as compare to medicine and surgery is less so, there might be participants who become worrying about the opportunity to work in the pediatric area

Table 7: Factors affecting the utilization of NRP training Programme

\begin{tabular}{|l|l|l|l|l|l|}
\hline $\begin{array}{l}\text { S. } \\
\text { No. }\end{array}$ & \multicolumn{5}{|l|}{$\begin{array}{l}\text { Factors affecting the utilization of NRP training } \\
\text { Programme. }\end{array}$} \\
\cline { 2 - 6 } & $\begin{array}{l}\text { Factors is } \\
\text { important } \\
\text { Yes/No) }\end{array}$ & $\begin{array}{l}\text { Yes. } \\
\text { Frequen } \\
\text { cy }\end{array}$ & $\begin{array}{l}\text { Percent } \\
\text { age }\end{array}$ & $\begin{array}{l}\text { Frequ } \\
\text { ency }\end{array}$ & $\begin{array}{l}\text { Percen } \\
\text { tage }\end{array}$ \\
\hline 1. & Time & 270 & $97.12 \%$ & 8 & $2.87 \%$ \\
\hline 2. & Transport & 213 & $76.61 \%$ & 65 & $23.38 \%$ \\
\hline 3. & Opportunity & 266 & $95.68 \%$ & 12 & $4.32 \%$ \\
\hline 4. & $\begin{array}{l}\text { Good/Bad family } \\
\text { situations }\end{array}$ & 165 & $59.35 \%$ & 113 & $40.64 \%$ \\
\hline 5. & Fear & 178 & $64.02 \%$ & 100 & $35.97 \%$ \\
\hline 6. & $\begin{array}{l}\text { Continuity to work } \\
\text { in Pediatric set-up. }\end{array}$ & 267 & $96.04 \%$ & 11 & $3.95 \%$ \\
\hline 7. & $\begin{array}{l}\text { Soft skills / } \\
\text { Communication }\end{array}$ & 266 & $95.68 \%$ & 12 & $4.31 \%$ \\
\hline 8. & Finance & 219 & $78.77 \%$ & 59 & $21.22 \%$ \\
\hline $\mathbf{9 .}$ & $\begin{array}{l}\text { Confidence/ Good } \\
\text { skills }\end{array}$ & 245 & $88.12 \%$ & 33 & $11.87 \%$ \\
\hline 10. & $\begin{array}{l}\text { Nonverbal } \\
\text { limitations. }\end{array}$ & 204 & $73.38 \%$ & 74 & $26.61 \%$ \\
\hline
\end{tabular}

The above table shows that the participants response to ten factors affecting or influencing the utilization of the NRP Training Programme. The majority of participants $270(97.10 \%)$ responded time is a significant issue, the second big collection of participants 267(96.1\%) responded Continuity to work in a Pediatric set-up is an essential factor. The third big group of participants $266(96 \%)$ responded opportunity is an required factor. The next large group of participants $262(94.20 \%)$ responded Soft skills and communication is an important factor. The next huge group of participants $245(88.10 \%$ ) responded Confidence/ Good skills is a vital factor. The next large group of participants $219(78.80 \%)$ responded Finance is an important factor. The next large group of participants $213(77 \%)$ responded transport is an imperative factor. The next bulky group of participants 204 (73.40\%) responded Nonverbal limitations is a chief factor. The next large group of participants $178(68 \%)$ responded fear is a central factor. The next hefty group of participants $165(59.40 \%)$ responded Good/Bad family situations is a main factor.

Table 9: Variation Of Importance In Factors Affecting Utilization: $\mathbf{N}=278$

\begin{tabular}{|l|l|l|l|l|}
\hline $\begin{array}{l}\text { S. } \\
\text { No. }\end{array}$ & $\begin{array}{l}\text { Very } \\
\text { Important } \\
\mathbf{> 7 0 \%}\end{array}$ & $\begin{array}{l}\text { Medium } \\
\text { Important } \\
\text { 36 to 70\%. }\end{array}$ & $\begin{array}{l}\text { Less } \\
\text { Important } \\
>70 \%\end{array}$ \\
\hline 1 & Time & $\sqrt{ }$ & --- & --- \\
\hline 2 & Transport & $\sqrt{ }$ & --- & --- \\
\hline 3 & Opportunity & $\sqrt{ }$ & --- & --- \\
\hline 4 & $\begin{array}{l}\text { Good/Bad family } \\
\text { situations }\end{array}$ & - & $\sqrt{ }$ & --- \\
\hline 5 & Fear & --- & $\sqrt{ }$ & --- \\
\hline 6 & $\begin{array}{l}\text { Continuity to work } \\
\text { in Pediatric set-up. }\end{array}$ & $\sqrt{ }$ & --- & --- \\
\hline
\end{tabular}




\begin{tabular}{|l|l|l|l|l|}
\hline 7 & $\begin{array}{l}\text { Soft skills / } \\
\text { Communication }\end{array}$ & $\sqrt{ }$ & --- & -- \\
\hline 8 & Finance & $\sqrt{ }$ & --- & --- \\
\hline 9 & $\begin{array}{l}\text { Confidence/Good } \\
\text { skills }\end{array}$ & $\sqrt{ }$ & --- & --- \\
\hline 10 & $\begin{array}{l}\text { Nonverbal } \\
\text { limitations. }\end{array}$ & $\sqrt{ }$ & --- & --- \\
\hline
\end{tabular}

The above table categories into the difference in importance of factors, where it shows that Very important factors are Time, Transport, Opportunity, Continuity to work in the pediatric area, Soft skills/communication, Confidence, Good skills \& Nonverbal limitations and Medium important factors are Good/Bad fly situations and Fear whereas Less important factors has not a single factor. It means, all the factors are import in the utilization of the NRP training programme.

\section{Other Factors Participants Feel.}

1. Availability of Instruments, Standard set - up.

2. Mental status of participants.

3. Knowledgeable \& Skilled members in a team.

4. Periodic \& timely course renewal.

5. Ease of education and simulation.

6. Knowledge update.

7. Maintenance of Group ratio.

8. Motivation by provision of incentives to nurses of critical area.

9. Interest of facilitator.

10. Overall attitude

\section{DISCUSSION:}

\section{- Personal Profile:}

The personal profile starts that the age of the participants where the majority participants $138(49.60 \%)$ aged between 26 to $30 y$ rs of age and less 39 (14\%) participants between 21 to $25 \mathrm{yrs}$ of age which young and strong group working in different health care establishments.

The gender population is majority $212(76 \%)$ were female whereas less $65(23 \%)$ population were male and surprisingly $1(040 \%)$ found in unspecified sex category all the participants working in different health care establishments. The income range categorizes as (Kuppuswamy classification) and the majority income range is $162(58.30 \%)$ of the population is between 23,674 to 47,347 Rs. whereas less found in $2(0.7 \%) 7,102$ to 11,886 Rs. Presently the minimum wedges for the employee are 15,000/-Rs so, the researcher had verbal communication and participants responded as either they working in a small hospital, the reason for working in the hospital is near to home or they do not join for working so, they put minimum wedges in the given column of response.

There were six different categories of the family included in the study and the majority found $148(53.20 \%)$ belongs to the Nuclear family and less $1(0.40 \%)$ found in the childless and extended family whereas, nobody found in a stepfamily.

There were seven different categories of primary education of the participants included in the study and the majority 108 $(38.80 \%)$ found in the professional degree researcher put the slot for professional degree separately and he assumes professional degree rather than nursing professional degree but I found a majority in professional degree this might be related to nursing profession whereas, less $2(0.70 \%)$ found in High school education and found nobody in primary school and illiterate.

The marital status of the participants shows that the majority $179(64.40 \%)$ were married and less $99(35.60 \%)$ were unmarried whereas nobody was widow or widower. There were five categories included in the No. of children category

where the majority $78(58.90 \%)$ participants found in not applicable. It means the participants are unmarried whereas, less than $1(0.40 \%)$ participants found more than two children.

There were four categories included in the distance of the home to the job where it founds the majority $123(44.20 \%)$ were staying within 1 to 3 kilometres of radius and less $22(7.90 \%)$ were staying within 7 to 10 kilometres of the radius.

\section{- Professional profile:}

The Professional profile starts with the Participants training where it included six categories and the majority of $109(39.20 \%)$ participants trained in GNM and less were trained in $4(1.40 \%)$ in $\mathrm{Ph} \mathrm{D}$ scholar and $\mathrm{Ph} \mathrm{D}$ in Nursing. Around 97(34.90\%) participants were trained in B Sc Nursing. It is also identified working health establishment of the participants where majority $192(69.10 \%)$ participants responded that they working in the private hospital like Himalayan Hospital which is a part of Swami Rama Himalayan University at Dehradun because the researcher included convenient sampling technique which is an easily accessible population nearby researcher and Swami Rama Himalayan University (SRHU) was the most convenient place from where majority participants included.

The next variable is the clinical experience of the participants which included six categories where the majority $131(47 \%)$ is 2 to5yrs. Whereas a minimum of $11(4 \%)$ participants found in less than one year and none experience. It shows that $11(4 \%)$ do not have any clinical experience and they attended the $\mathrm{NRP}$ training programme. It also has more concerned in less than one year of clinical experience.

The next variable is the teaching experience of the participants which included five categories where the majority $139(50 \%)$ is 2 to5yrs. Whereas a minimum of $26(9.40 \%)$ participants found in more than ten years of experience.

The duration of work in the current area is important in significant area point of view where the majority $139(50 \%)$ participants were found in 2to5yrs Whereas minimum of $26(9.40 \%)$ in more than ten years of experience.

As the NRP training has special importance for those participants who are registered in a different association like SNA \& TNAI. The researcher also investigated this variable where it is found that the majority $86(30.90 \%)$ had none of the above registration and, minimum of $50(18 \%)$ participants found both SNA \& TNAI registration.

The next variable included "Participants exposure to related work clinical area after or before NRP training" which include six categories of significant clinical are where majority $85(31 \%)$ participants found working in other speciality unit and less 15(5.40\%).Working in another gynecological unit.

The last variable in the professional profile is "Service Gap" where the majority $254(91.40 \%$ ) had no gap in service which is good and less than $4(1.40 \%)$ participants has more than 2yrs of gap in service.

\section{- UTILIZATION OF NRPTRAINING PROGRAMME}

The majority $163(58.63 \%)$ nurses utilized the NRP training skills and $115(41.36 \%)$ nurses could not able to utilize the NRP training skills adequately. It also indicated the NRP training Programme was utilized among nurses working in different health establishment. The utilized skills nurses had exposure to your NRP skills, renewed the Course post certificate expiration, Willingness to renew NRP course in future, No difficulties/setbacks for the renewing the NRP course, Having difficulties and set back they are ready to renew the NRP course, Participants had an opportunity to demonstrate NRP training skills, Participants were willing to 
utilize your NRP skills aggressively after they renew their NRP Course. These are some of the points where participants agreed positively that depicts the utilization of NRP skills. Those who not utilized are given some negative responses thus the percentage comes out of non-utilization but, the good output is the majority of participants had the utilization of NRP skills.

\section{LIMITATION:}

1. Study was confined to Nurses who attended NRP workshop from 2012 to 2015

2. Study was limited to Nurses who responded to the online questionnaire.

3. Study was limited to a period of 3 months ( 90 days) due to the potential threat of pandemic for data collection.

4. Study was limited to nurses who attended the NRP workshop at the selected centre.

5. Study was limited to nurses who can read, understand English well.

6. There was no random selection of samples.

\section{CONCLUSION:}

The participants response to ten factors affecting or affecting/influencing the utilization of the NRP Training Programme. The majority of participants responded time is a significant issue, the second big collection of participants responded Continuity to work in a Pediatric set-up is an essential factor. The third big group of participants responded opportunity is a required factor. The next large group of participants responded Soft skills and communication is an important factor. The next huge group of participants responded Confidence/ Good skills is a vital factor. The next large group of participants responded Finance is an important factor. The next large group of participants responded transport is an imperative factor. The next bulky group of participants responded Nonverbal limitations is a chief factor. The next large group of participants responded fear is a central factor. The next hefty group of participants responded Good/Bad family situations is a main factor.

\section{ACKNOWLEDGEMENT:}

I would like to acknowledge through my sincere thanks to Dr. V. P. Goswami NRP President 2018 and National nodal person IAP - NNF - NRP - FGM 2016 - 2017. And his entire team for providing permission and provision of necessary information supporting in favor to conduct the study.

\section{CONFLICT OF INTEREST: None.}

\section{REFERENCES:}

1. The message, Ghulam Nabi Azad, former union minister for health and family welfare, India Govt.

2. Forward Address by Naresh Dayal, former health and family welfare, secretary Govt. of India "Basic newborn care and resuscitation program training manual.

3. Message from mission director (NRHM), P.K. Pradhan, Additional Secretary, and mission director, (NRHM), Ministry of health and fly welfare, Govt. of India "Basic newborn care and resuscitation program training manual.

4. Ray SK. Awareness and Utilization of national rural health mission ser-vices among people of selected rural areas in the state of Maharashtra. Natl J Community Med. 2014;5:387-91

5. Luo YF, Yang SC, Chen AS, Chiang CH. Associations of ehealth literacy with health services utilization among college students: cross-sectional study. Journal of medical Internet research. 2018;20(10):e283. 